\title{
Distinct domains in Nbs1 regulate irradiation-induced checkpoints and apoptosis
}

\author{
Simone Difilippantonio, ${ }^{1}$ Arkady Celeste, ${ }^{1}$ Michael Kruhlak, ${ }^{1}$ \\ Youngsoo Lee, ${ }^{2}$ Michael J. Difilippantonio, ${ }^{3}$ Lionel Feigenbaum, ${ }^{4}$ \\ Stephen P. Jackson, ${ }^{5}$ Peter J. McKinnon, ${ }^{2}$ and André Nussenzweig ${ }^{1}$ \\ ${ }^{1}$ Experimental Immunology Branch and ${ }^{3}$ Genetics Branch, National Cancer Institute, National Institutes of Health, \\ Bethesda, MD 20892 \\ 2Department of Genetics and Tumor Cell Biology, St. Jude Children's Research Hospital, Memphis, TN 38105 \\ ${ }^{4}$ SAIC-Frederick, National Cancer Institute-Frederick Cancer Research and Development Center, Frederick MD 21702 \\ ${ }^{5}$ Wellcome Trust/Cancer Research U.K. Gurdon Institute and the Department of Zoology, University of Cambridge, \\ Cambridge CB2 10N, England, UK
}

CORRESPONDENCE

André Nussenzweig:

andre_nussenzweig@nih.gov
Mre11, Rad50, and Nbs1 (MRN) form an evolutionarily conserved protein complex that mediates diverse functions critical for maintaining genomic stability (1-9). Loss of function mutations in mice lead to early embryonic lethality in vertebrates (10-12), which reflects the essential role of the complex in DNA recombination during normal replication (9, 13-15). In addition to its critical function during $S$ phase, MRN influences the induction of cellcycle checkpoints in response to DNA damage away from replication forks. This checkpoint function has been linked to MRN's role as an upstream activator $(1-5,7,16-19)$ and a downstream target of the ataxia telangiectasia mutated (ATM) kinase (20-23).

MRN complexes become associated with double-strand breaks (DSBs) within seconds after DSB formation (24). Once bound, MRN

$\overline{\text { The online version of this article contains supplemental material. }}$ attracts the ATM kinase to the DSB site by several mechanisms, including direct interactions between ATM and a conserved C-terminal region in $\mathrm{Nbs} 1(7,25,26)$. In the presence of an intact MRN complex, ATM becomes activated by an as yet undefined mechanism (27-29) and phosphorylates numerous substrates, including Nbs1 at residues S278 and S343 (20-23). This is followed by an escalating accumulation of MRN and other proteins into irradiation (IR)-induced foci, corresponding to large chromatin domains flanking the DSB (30). The primary function of this large-scale chromatin retention may be to amplify the DSB signal (31). If the damage or DSB signal is too severe, the cell undergoes programmed cell death, which is partially dependent on the activity of ATM $(32,33)$.

Ectopic expression of mutated Nbs1 constructs into Nijmegen breakage syndrome (NBS) patient cell lines, which harbor hypomorphic mutations in Nbs1 $(34,35)$, have been 
used to determine the role of distinct Nbs1 domains in the activation of ATM and its downstream effectors. The N-terminal forkhead-associated (FHA) and BRCT domains of Nbs1, although dispensable for localization of MRN to the nucleus, are required for the accumulation of $M R N$ into IR-induced foci $(36,37)$. The association with chromatin is mediated by interactions between the FHA and BRCT domains of Nbs1 and MDC1 and $\gamma$-H2AX $(24,38,39)$. The N-terminal domain has been reported to be essential for cell survival in response to IR, optimal activation of ATM, and for the intra-S phase checkpoint $(2,3,26,36,37,40,41)$. In addition to the FHA domain, ATM-dependent phosphorylations of Nbs1 at Ser278 and S343, as well as structural maintenance of chro- mosomes (SMC) 1 at S957 and S966, regulate the intra-S phase checkpoint $(20-23,42,43)$. It remains unclear how the FHA phosphothreonine-specific protein-protein interaction motif (44) is linked with S phase checkpoint-specific phosphorylations, although it has been reported that mutations in the Nbs1 FHA domain impair ATM-dependent Nbs1 but not SMC1 phosphorylation $(2,26,36,37)$. One report (45), but not others $(2,42)$, has concluded that Nbs1 phosphorylation is required for SMC1 phosphorylation.

The evolutionarily conserved C-terminal 20 aa of Nbs1 interact with ATM $(25,46,47)$. Transfection of Nbs1 deleted in the C-terminal domain $(\mathrm{Nbs} 1 \Delta \mathrm{C})$ did not complement NBS cells, as indicated by the impairment in ATM and
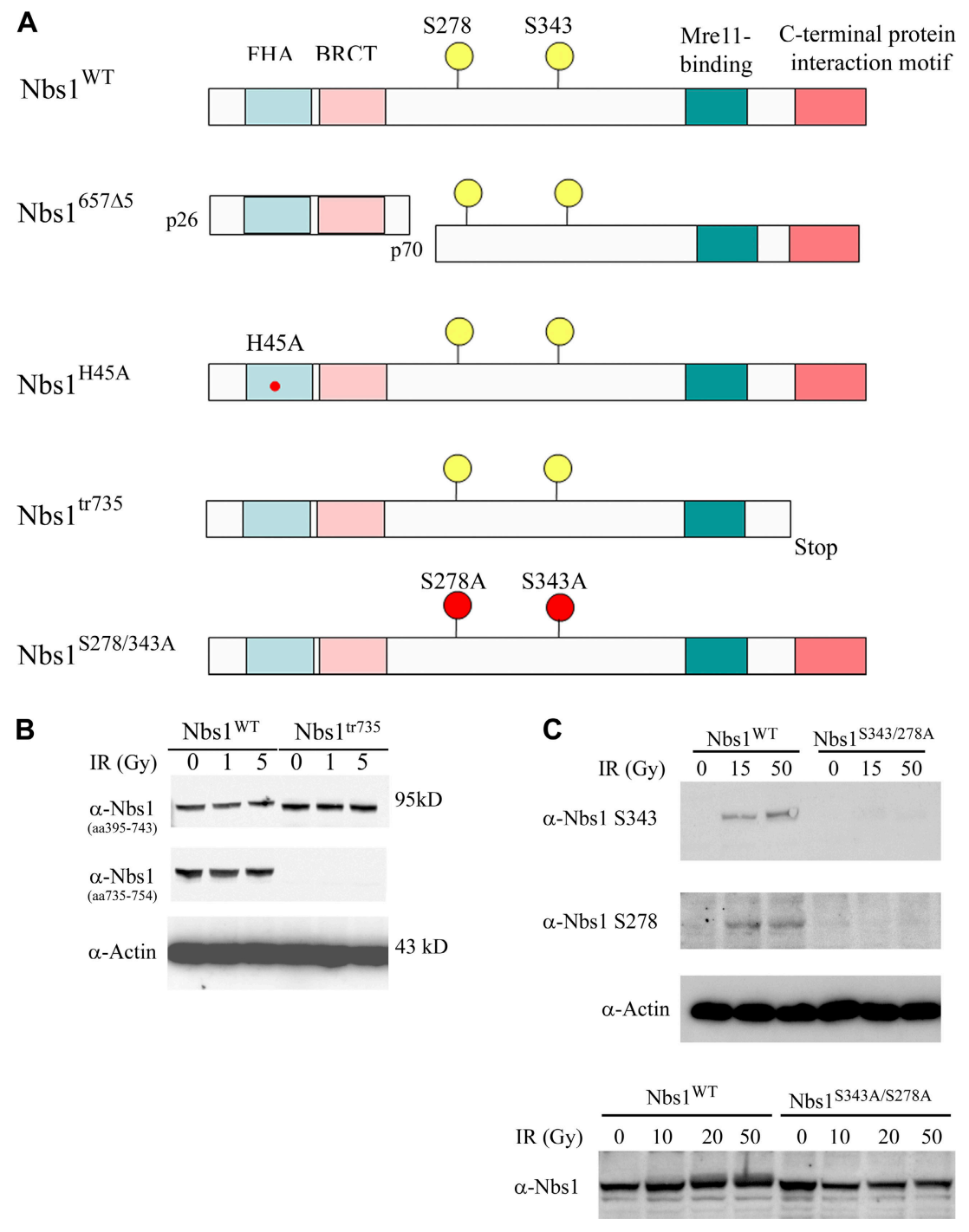

Figure 1. Expression of human Nbs1 mutants from a BAC transgene in mice deficient for mNbs1. (A) Diagram of Nbs1 $1^{\mathrm{WT}}, \mathrm{Nbs} 1^{657 \Delta 5}$, Nbs $1^{\mathrm{H} 45 \mathrm{~A}}$,

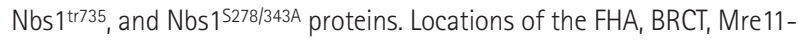
binding domains, S278 and S343 phosphorylation sites, and the conserved C-terminal protein interaction are shown. (B) Generation of mice harboring

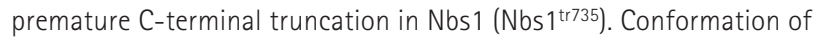

expression by reduced size using an Nbs1 antibody raised against aa 395-743. Another Nbs1 antibody that was raised against the last 20 aa of Nbs1 (aa 735-754) does not recognize the Nbs $1^{\text {tr735 }}$ mutant species. (C) Generation of mice expressing the Nbs1 phosphorylation mutant, Nbs1 ${ }^{\text {S278/343A. }}$ Absence of phosphorylation was confirmed using phosphospecific antibodies and reduced mobility shift of mutant Nbs1 after IR (doses as indicated). 
downstream target phosphorylations and checkpoint defects in response to IR $(25,26)$. Moreover, $\mathrm{Nbs} 1 \Delta \mathrm{C}$ did not stimulate DSB-induced ATM autophosphorylation in Xenopus egg extracts (46). These phenotypes are correlated with the failure to stimulate ATM recruitment to sites of DSBs $(25,46)$ and to convert ATM dimers to active monomers (48). Thus, all studies to date indicate that activation of ATM after DSB formation requires interaction with the $\mathrm{Nbs} 1 \mathrm{C}$ terminus.

One potential confounding issue in these studies is that the cell lines used to assess the various Nbs1 mutants expressed a hypomorphic allele of NBS (49). This results in expression of a C-terminal species $\left(\mathrm{Nbs}^{\mathrm{p}} \mathrm{p}^{70}\right)$ lacking FHA/ BRCT domains but containing ATM phosphorylation sites, as well as domains necessary for interaction with Mre11 and ATM (49) that can fulfill the essential functions of the MRN complex. Moreover, the $\mathrm{Nbs} 1^{\mathrm{p} 70}$ species varies widely between different NBS cell lines, being expressed at high levels in lymphoblastoid cells and undetectable in fibroblasts (49). Therefore, it is possible that the biological impact of expressing various Nbs1 mutants in the context of this variant C-terminal species may be quite different from reconstitution of a true Nbs1-null cell line. Finally, the cell lines used in transfection studies were either immortalized or transformed, making the impact of additional mutations unpredictable.

To circumvent these difficulties, we established a robust system whereby we reconstitute Nbs1 knockout mice with human bacterial artificial chromosome (BAC) transgenes carrying specifically engineered mutations in different $\mathrm{Nbs} 1 \mathrm{do-}$ mains. This has enabled us to analyze and evaluate the impact of these mutations in primary cells of different origin and within the context of the entire organism.

\section{RESULTS AND DISCUSSION}

To determine the role of various $\mathrm{Nbs} 1$ domains in affecting ATM activity, we used BAC recombineering to mutate a BAC clone (255A7) containing the human Nbs1 gene, which was previously demonstrated to rescue the embryonic lethality and completely reconstitute Nbs1 knockout mice (7). Five BAC transgenes were crossed into an endogenous Nbs1-deficient background (Fig. 1 A): (a) Nbs1 ${ }^{\mathrm{WT}}$, which expresses the human WT BAC (7); (b) Nbs1 $1^{657 \Delta 5}$, which is a 5-bp deletion that leads to the expression of a hypomorphic allele that is described in $95 \%$ of NBS patients $(7,34,35)$; (c) $\mathrm{Nbs} 1^{\mathrm{H} 45 \mathrm{~A}}$, which is a point mutation in the FHA domain $(7,37)$; (d) $\mathrm{Nbs}^{\text {tr735, which }}$ is a truncated derivative lacking the C-terminal 20 aa residues; and (e) $\mathrm{Nbs}^{\mathrm{S} 278 \mathrm{~A} / \mathrm{S} 343 \mathrm{~A}}$, which carries two mutations in which the serine S278 and S343 residues are modified to alanine. All of these constructs rescued the embryonic lethality of the Nbs1null mutation, as mice were born at predicted Mendelian frequencies in intercrosses between transgene ${ }^{+} \mathrm{Nbs}^{+/-}$mice.

We confirmed the presence of the mutations in the BAC by sequence analysis (not depicted) and verified protein

A
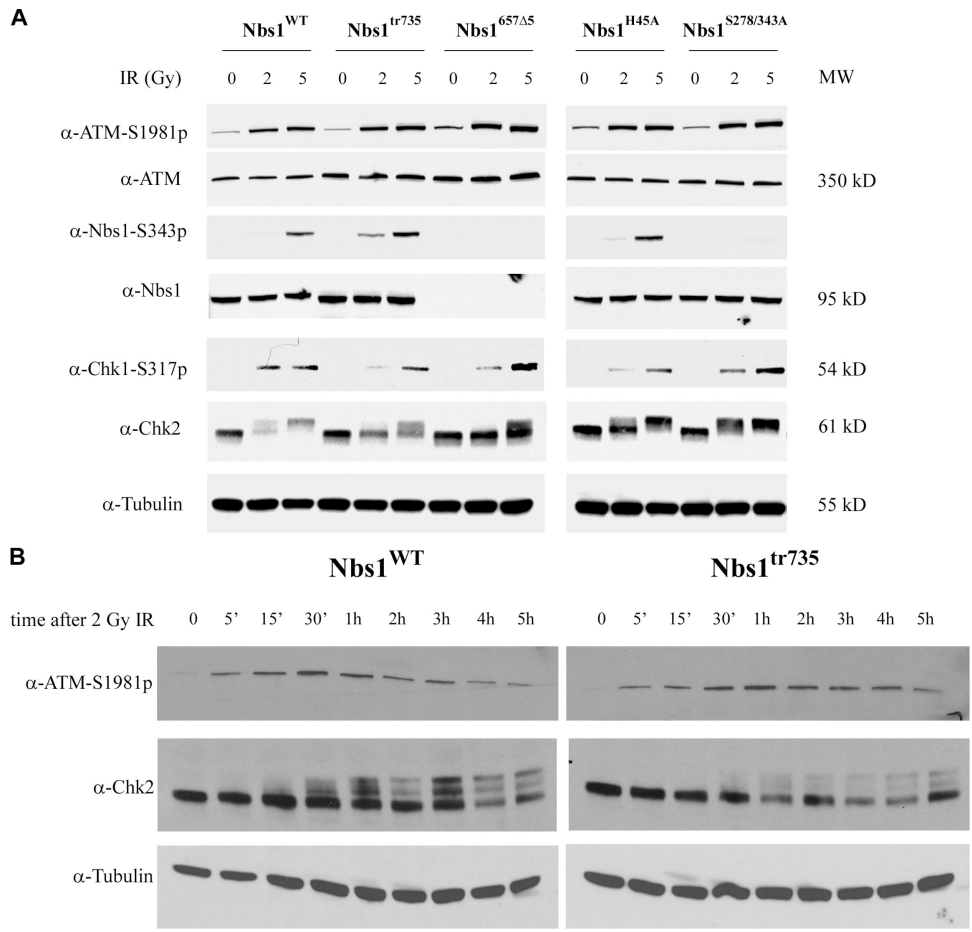

Figure 2. ATM and ATM substrate phosphorylation in primary B cells. (A) B cells were stimulated for $48 \mathrm{~h}$ and harvested for Western blot analysis 30 min after no treatment ( 0 Gy) or after $\gamma$ IR (2 and 5 Gy) and immunoblotted with phosphospecific anti-ATM Ser 1981p, anti-Chk1 Ser $317 p$, and anti-Nbs1 Ser343p antibodies, as well as panspecific
anti-ATM, anti-Nbs1, and anti-Chk2 antibodies. Phosphorylation of Chk2 is indicated by the mobility shift. (B) B cells from Nbs $1^{\mathrm{WT}}$ and Nbs $1^{\text {tr735 }}$ mice were treated with 2 Gy of ionizing radiation, and extracts were prepared at the indicated time points after IR and immunoblotted as indicated. 
expression and size by Western blot analysis (Fig. 1 and Fig. $2 \mathrm{~A}) . \mathrm{Nbs}^{\mathrm{tr} 735}$ and $\mathrm{Nbs} 1^{\mathrm{S} 278 \mathrm{~A} / \mathrm{S} 343 \mathrm{~A}}$ proteins were expressed at similar levels (within 1.5-fold) as the full-length Nbs1 ${ }^{\mathrm{WT}}$ transgene (Fig. 1, B and C). Nbs $1^{\text {tr735 }}$ mice produced a truncated protein, as indicated by the fact that antibodies against the Nbs1 C terminus (aa 735-754) (50) failed to detect the protein, whereas the protein was detected using an antibody that recognizes the $\mathrm{N}$ terminus (aa 395-743; Fig. 1 B). Phoshospecific antibodies generated against S278 and S343 detected phosphorylated forms of $\mathrm{Nbs} 1$ in $\mathrm{Nbs} 1^{\mathrm{WT}}$ mice but not in $\mathrm{Nbs}^{\mathrm{S} 278 \mathrm{~A} / \mathrm{S} 343 \mathrm{~A}}$ mice (Fig. $1 \mathrm{C}$ ). Moreover, we detected a substantial reduction of IR-induced mobility shift in Nbs1 when thymocytes from Nbs1 $1^{\text {S278A/S343A }}$ were irradiated (Fig. 1 C). Nevertheless, it is possible that other sites within Nbs1 besides S278 and S343 could be phosphorylated in $\mathrm{Nbs}^{\mathrm{S} 278 \mathrm{~A} / \mathrm{S} 343 \mathrm{~A}}$ mice in response to IR (22).

To determine whether Nbs1 mutants can still form a functional complex with Mre11/Rad50, we performed immunoprecipitation and immunofluorescence analyses on mouse embryo fibroblasts (MEFs; Fig. S1 and Fig. S2, available at http://www.jem.org/cgi/content/full/jem.20070319/DC1). Although the interaction with $\mathrm{Nbs} 1$ and nuclear localization of Mre11 were not affected in $\mathrm{Nbs} 1^{\mathrm{H} 45 \mathrm{~A}}$ and $\mathrm{Nbs} 1^{\text {tr735 }}$ mutant cells, foci formation was dependent on the intact FHA domain but not on the $\mathrm{C}$ terminus, as expected ( 7 , $25,36,37)$.

A

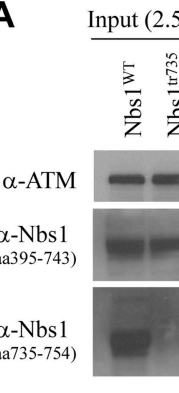

We have previously reported that $\mathrm{Nbs} 1^{\mathrm{H} 45 \mathrm{~A}}$ mice share many overlapping phenotypes with $\mathrm{Nbs} 1^{657 \Delta 5}$ mice, including defective thymocyte and oocyte development, genomic instability, and a reduction in phosphorylation of the ATM downstream target Chk2 at low IR doses (7). These phenotypes are similarly observed, but more severe, in ATM knockout mice. In contrast, $\mathrm{Nbs} 1^{\mathrm{S} 278 \mathrm{~A} / \mathrm{S} 343 \mathrm{~A}}$ and $\mathrm{Nbs} 1^{\text {tr7735 }}$ mice were fertile and did not exhibit any detectable defect in $\mathrm{B}$ cell or $\mathrm{T}$ cell development (not depicted). Moreover, Nbs1 $1^{\text {tr735 }}$ MEFs did not show more $\gamma$ IR-induced chromosomal aberrations relative to Nbs1 ${ }^{\mathrm{WT}}$ (Fig. S3, available at http://www.jem.org/cgi/ content/full/jem.20070319/DC1). To examine the cellular DNA damage signaling response, we measured ATM autophosphorylation and substrate phosphorylation in primary $\mathrm{B}$ cells in response to $\gamma$ IR (Fig. $2 \mathrm{~A}$ ). In Nbs1 $1^{\mathrm{S} 278 \mathrm{~A} / \mathrm{S} 343 \mathrm{~A}}$ mice, there was no detectable defect in phosphorylation of ATM, Chk1, or Chk2. In contrast, a small reduction in the magnitude of some ATM substrate phosphorylations, particularly Chk1S317p and Chk2p was apparent in $\mathrm{Nbs} 1^{657 \Delta 5}, \mathrm{Nbs}^{\mathrm{H} 45 \mathrm{~A}}$, and $\mathrm{Nbs} 1^{\text {tr735 }}$ B cells treated with a low dose (2 Gy) of IR. Consistent with inefficient substrate phosphorylation at low but not high doses of IR, the kinetics of Chk2 phosphorylation were perturbed in primary $\mathrm{Nbs}^{\mathrm{tr} 735} \mathrm{~B}$ cells relative to WT controls after 2 Gy (Fig. 2 B), but normal after 8 Gy, of IR (not depicted).

The finding that DSB signaling was not profoundly affected in $\mathrm{Nbs}^{\mathrm{tr} 735}$ mice was particularly surprising given that

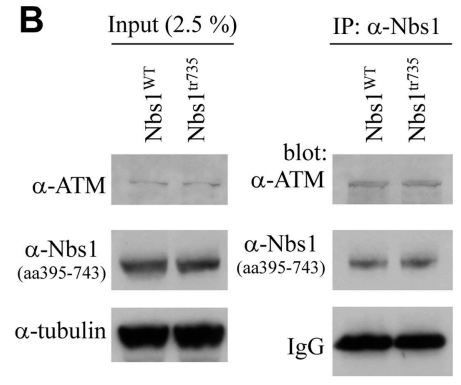

C

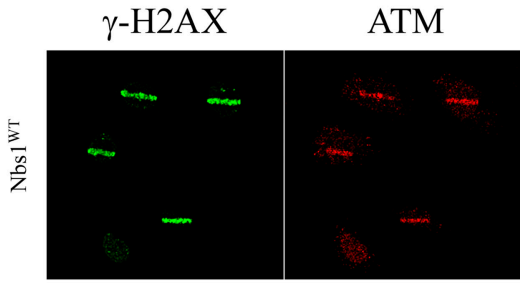

DIC

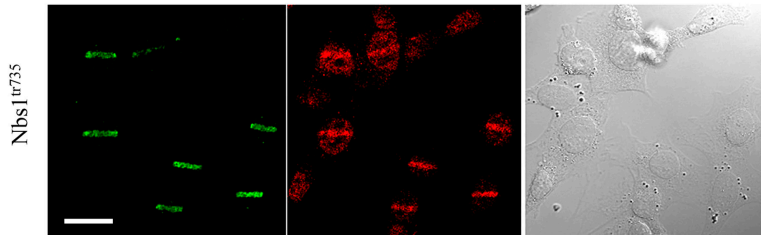

Figure 3. DNA damage induced ATM-Nbs1 interaction and recruitment of ATM to DNA breaks. (A and B) B cells from Nbs $1^{\text {WT }}$ and $\mathrm{Nbs} 1^{\mathrm{tr} 735}$ mice were treated with 2 Gy of ionizing radiation, and extracts were prepared 30 min after IR and immunoprecipitated with anti-ATM (A) or anti-Nbs1 (B) and immunoblotted as indicated. (C) Distribution of ATM (red) in Nbs $1^{\text {WT }}$ and Nbs $1^{\text {tr735 }}$ MEFs 5 min after treatment with UV laser microirradiation. $\boldsymbol{\gamma}-\mathrm{H} 2 \mathrm{AX}$ (green) marks sites of DSBs. Digital camera images reveal the individual cells. Bar, $25 \mu \mathrm{m}$. 
transfection of $\mathrm{Nbs} 1 \Delta \mathrm{C}$ into NBS cell lines failed to complement ATM and substrate phosphorylations $(25,26)$. To determine whether $\gamma$ IR-induced signaling was indeed ATM dependent, we pretreated B cells with a small molecule inhibitor of ATM (KU55933) (51) before IR. Treatment with the ATM inhibitor blocked the phosphorylation of ATM, SMC1, Chk1, and Chk2 in Nbs1 ${ }^{\mathrm{WT}}$, Nbs1 ${ }^{657 \Delta 5}, \mathrm{Nbs} 1^{\mathrm{H} 45 \mathrm{~A}}$, and $\mathrm{Nbs}^{\text {tr735 }}$ mice (Fig. S4, available at http://www.jem .org/cgi/content/full/jem.20070319/DC1), indicating that ATM mediates substrate phosphorylations in these mice.

To determine if the Nbs1 C-terminal domain is required for interaction with ATM, we performed immunoprecipitation analysis (Fig. 3, A and B). We were able to coimmuno-

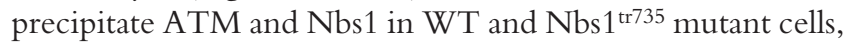

indicating that the deletion of the Nbs1 C terminus clearly did not abrogate the Nbs1-ATM interaction (Fig. 3, A and B). To determine whether ATM is still capable of being recruited to DNA damage in Nbs1 $1^{\text {tr735 }}$ cells, we induced DSBs in primary and mutant fibroblasts using a laser microbeam. The assembly of ATM coincident with $\gamma$-H2AX-marked sites of DSBs was tracked by fluorescence microscopy. We found rapid recruitment of ATM to DSBs independent of Nbs1 status (Fig. $3 \mathrm{C}$ ). The fact that the Nbs1 C-terminal domain is dispensable for interaction with ATM and ATM recruitment to DSBs may explain why DSB signaling is not ablated in $\mathrm{Nbs}^{\mathrm{tr} 735}$ mice.

NBS cells, which express a hypomorphic allele identical to our BAC-encoded Nbs1 $1^{657 \Delta 5}$ transgene, show cell-cycle
A
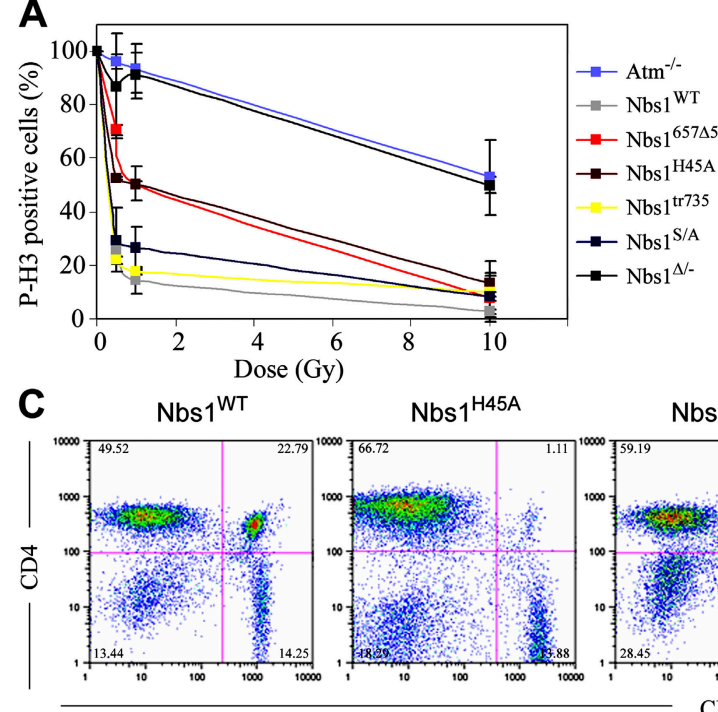

D

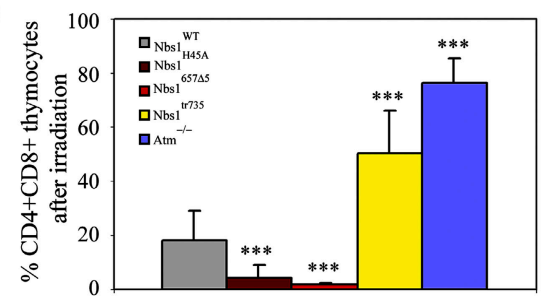

Figure 4. Cell-cycle checkpoints, IR sensitivity, and apoptosis in Nbs1 mutants. (A) Comparison of the G2/M checkpoint in Nbs 1 WT, $\mathrm{Nbs} 1^{657 \Delta 5}, \mathrm{Nbs} 1^{\mathrm{H} 45 \mathrm{~A}}, \mathrm{Nbs} 1^{\text {tr735, }} \mathrm{Nbs}^{\mathrm{S} 278 / 343 \mathrm{~A}}, \mathrm{Nbs} 1^{\mathrm{\Delta l}-}$, and $\mathrm{Atm}^{-1-}$ mice. $\mathrm{B}$ cells were stimulated for $48 \mathrm{~h}$ and irradiated with the indicated dose, and the mitotic cells (positive for phosphorylated histone $\mathrm{H} 3$ [P-H3]) were measured by flow cytometry $1 \mathrm{~h}$ after IR. The percentage of $\mathrm{P}-\mathrm{H} 3-$ positive cells (unirradiated/irradiated) is plotted for each genotype. Data are representative of at least three independent experiments. Error bars indicate the standard deviation. (B) The intra-S phase checkpoint in

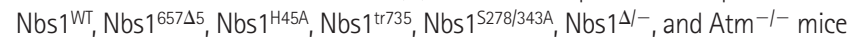
as a function of IR dose. B cells were stimulated for $48 \mathrm{~h}$ and irradiated with the indicated dose, and thymidine uptake was assessed $4 \mathrm{~h}$ after IR. Data from triplicate samples are normalized to the counts in unirradiated controls. Data are representative of at least three independent experi-

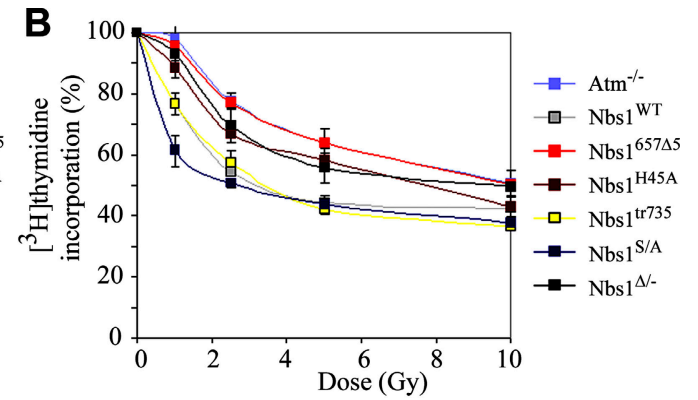

$\mathrm{Nbs} 1^{657 \Delta 5} \quad \mathrm{Nbs} 1^{\mathrm{tr} 735} \quad \mathrm{Atm}^{-/-}$

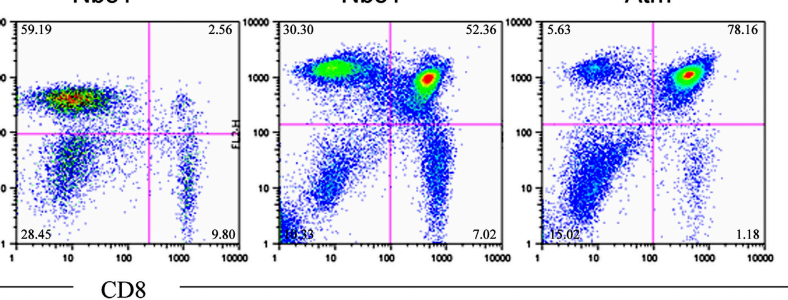

$\mathrm{CD} 8$

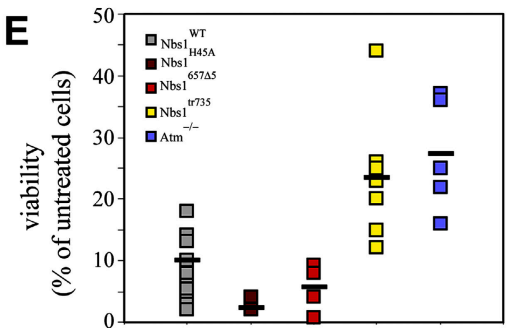

ments. Error bars indicate the standard deviation. (C) Sensitivity of thymocytes to IR. Mice were exposed to whole-body IR of $4 \mathrm{~Gy}$, and thymocytes were isolated $24 \mathrm{~h}$ later. The viability and percentage of CD4/ CD8 thymocytes were determined by propidium iodide staining and flow cytometry. Representative FACS profiles are shown. The numbers in the quadrants indicate the percentage of cells that express either CD4 or CD8 (CD4 ${ }^{-} \mathrm{CD} 8^{-}, \mathrm{CD}^{+}{ }^{+} \mathrm{CD} 8^{+}, \mathrm{CD} 4^{+} \mathrm{CD} 8^{-}, \mathrm{CD} 4^{-} \mathrm{CD} 8^{+}$). (D) Average of $\mathrm{CD} 4 / \mathrm{CD} 8$ $\mathrm{DP}$ thymocytes $24 \mathrm{~h}$ after IR with $4 \mathrm{~Gy}$ in vivo. Data are a summary from at least five independent experiments. Error bars indicate the mean \pm standard deviation. ${ }^{* *}, \mathrm{P}<0.001$ for Nbs1 ${ }^{\text {WT }}$ vs. Atm ${ }^{-1-}$, Nbs $1^{\text {WT }}$ vs. $\mathrm{Nbs} 1^{\text {tr735}}$, and Nbs $1^{\text {WT }}$ vs. Nbs $1^{\mathrm{H} 45 \mathrm{~A}}$, and Nbs $1^{{ }^{\mathrm{WT}}}$ vs. Nbs $1^{657 \Delta 5}$. (E) Average of total viable thymocytes $24 \mathrm{~h}$ after IR with $4 \mathrm{~Gy}$ in vivo. Data are a summary from at least five independent experiments. Horizontal lines represent means. 
checkpoint defects and sensitivity to IR. To determine which of the Nbs1 domains contribute to DNA damage-induced cell-cycle checkpoints, we treated primary B cells with $\gamma$ IR (Fig. 4, A and B). Nbs1 $1^{\mathrm{WT}}, \mathrm{Nbs}^{\mathrm{S} 278 \mathrm{~A} / \mathrm{S} 343 \mathrm{~A}}, \mathrm{Nbs} 1^{\mathrm{tr} 735}$, $\mathrm{Nbs} 1^{\mathrm{H} 45 \mathrm{~A}}, \mathrm{Nbs} 1^{657 \Delta 5}, \mathrm{Nbs}^{\Delta /-}$ (B cell-specific conditional null; reference 14), and $\mathrm{Atm}^{-1-} \mathrm{B}$ cells were assayed over a dose range of $0.5-10 \mathrm{~Gy} 1 \mathrm{~h}$ after IR. Although cells from $\mathrm{Nbs}^{\mathrm{\Delta}-}$ mice showed a reduction in the mitotic index similar in magnitude to Atm ${ }^{-/-}$cells, the G2/M checkpoint arrest was normal in $\mathrm{Nbs} 1^{\mathrm{WT}}$, $\mathrm{Nbs}^{1 \mathrm{tr} 735}$, and $\mathrm{Nbs} 1^{\mathrm{S} 278 / 343 \mathrm{~A}}$ mice. Intermediate defects were observed in cells from $\mathrm{Nbs} 1^{657 \Delta 5}$ and $\mathrm{Nbs} 1^{\mathrm{H} 45 \mathrm{~A}}$ mice (Fig. 4 A). Similar results were obtained when we assayed for thymidine incorporation after IR-induced DNA damage (Fig. 4 B). Again, only $\mathrm{Nbs} 1^{657 \Delta 5}, \mathrm{Nbs} 1^{\mathrm{H} 45 \mathrm{~A}}$, and $\mathrm{Nbs} 1^{\mathrm{\Delta}-}$ cells showed a reduction in the rate of DNA replication. Collectively, these results indicate that cell-cycle checkpoints are regulated by the DSB-induced activation of ATM through the MRN complex and that the Nbs1-FHA domain participates in eliciting a full cell-cycle checkpoint arrest. In contrast, neither the Nbs1 C terminus nor ATM-dependent phosphorylations at S278 and S343 are necessary for efficient checkpoint responses.

One hallmark feature of Atm ${ }^{-/-}$mice is the resistance of their immature thymocytes to IR-induced apoptosis (32). To examine the potential role of different Nbs1 domains in the apoptotic response, we subjected mice to whole-body IR (Fig. 4, C-E). Flow cytometric analysis of thymocytes from WT mice $24 \mathrm{~h}$ after treatment with 4 Gy confirmed that they were sensitive to IR. We observed a 93\% reduction in the total number of thymocytes (Fig. 4 E), and an ablation of the CD4/CD8 double-positive (DP) thymocyte population from $80-85 \%$ in control mice to $15-30 \%$ (average $18 \%$ ) remaining after IR (Fig. 4, C and D). As expected, ATM ${ }^{-/-}$ thymocytes were more resistant to apoptosis, showing a threefold increase in viability relative to the WT (Fig. 4 E) and a persistence of DP thymocytes accounting for $76 \%$ of the population (Fig. $4 \mathrm{D}$ ). Nbs1 $1^{\text {tr735 }}$ mice were about threefold more resistant to apoptosis than WT mice (Fig. 4 E), and on average $51 \%$ of the irradiated thymocytes were DP (Fig. 4 D). Consistent with this, the number of apoptotic cells was reduced in Nbs1 $1^{\text {tr735 }}$ thymi relative to the WT, as determined by apoptosis assays and the activation of caspase 3 in situ (Fig. S5, available at http://www.jem.org/cgi/content/ full/jem.20070319/DC1), and there was a reduction in phosphorylation at residue S15 of p53 (Fig. S6). In contrast, $\mathrm{Nbs} 1^{\mathrm{H} 45 \mathrm{~A}}$ and $\mathrm{Nbs} 1^{657 \Delta 5}$ thymocytes were exquisitely sensitive to IR, exhibiting an almost complete depletion in the CD4/ CD8 DP thymocyte population and reduced viability of total thymocytes compared with WT littermates (Fig. 4, C-E). Thus, the $\mathrm{N}$ and $\mathrm{C}$ terminus domains of $\mathrm{Nbs} 1$ have opposite effects on the induction of IR-induced thymocyte apoptosis.

By using a human BAC harboring endogenous regulatory elements of the Nbs1 gene, we have been able to assess the contribution of various domains of Nbs1 in stimulating divergent ATM-mediated DSB response pathways in vivo in the complete absence of other aberrant forms of the Nbs1 protein. As such, we arrive at surprisingly different results from what has as yet been reported (Fig. 5) $(25,26)$. In particular, the $\mathrm{C}$ terminus of $\mathrm{Nbs} 1$ was previously shown to bind to ATM and was required for recruitment of ATM to sites of DNA damage. Thus, one would predict that deletion of the Nbs1 C terminus in vivo would result in an AT-like phenotype. On the contrary, we find that $\mathrm{Nbs} 1^{\operatorname{tr} 735}$ mice harboring a premature truncation of $\mathrm{Nbs} 1$, resulting in a protein lacking this reported ATM binding domain, do not show any defects in lymphocyte or germ cell development in vivo and neither checkpoint defects nor genomic instability in vitro. However, we did observe attenuated Chk2 and Chk1 phosphorylations in response to low-dose IR. This indicates either that the activity of ATM is modestly compromised or that the C terminus regulates the optimal binding between ATM and specific substrates. Nevertheless, the association between $\mathrm{Nbs} 1 \Delta \mathrm{C}$ and ATM is sufficient for recruitment of ATM to sites of DNA damage and for nearly normal ATM activation.

One possibility for the observed discrepancy could be that in earlier studies $(25,26), \mathrm{Nbs} 1 \Delta \mathrm{C}$ protein was expressed in

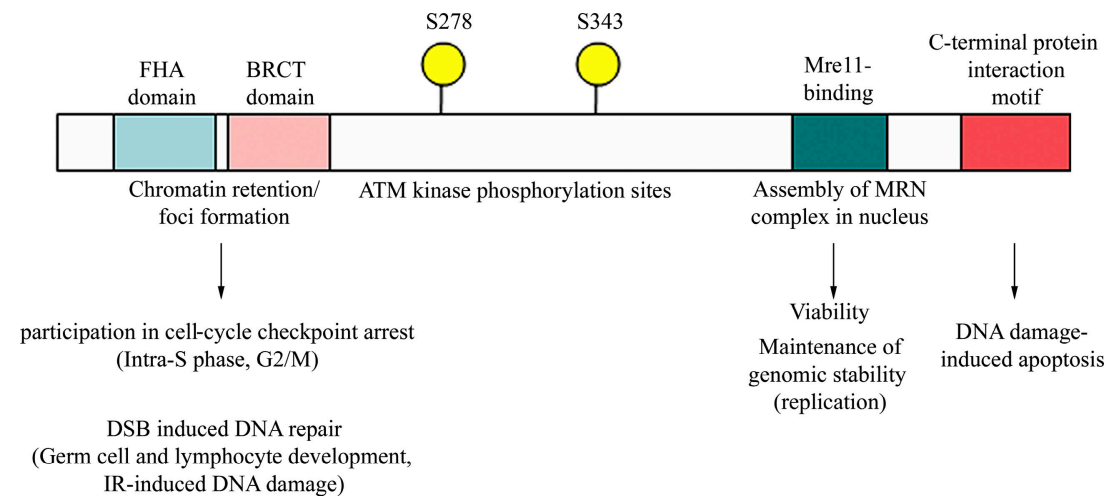

Figure 5. Map of different Nbs1 domains and their physiological function in vivo. Our results are consistent with the above model in which T cell and oocyte development and DNA damage induced G2/M and $S$ phase checkpoint arrest and radiation survival is dependent on the
$\mathrm{N}$-terminal FHA domain, but not on the principal residues phosphorylated by ATM (serine 278 and 343 ) or on the evolutionarily conserved $\mathrm{C}$-terminal region of Nbs1. The $\mathrm{C}$-terminal region regulates irradiationinduced apoptosis. 
hypomorphic NBS cells in contrast to a $\mathrm{Nbs}^{-/-}$background. It would be possible that simultaneous expression of two hypomorphic alleles could exacerbate the phenotypes. To address this issue, we have generated mice doubly transgenic for the $\operatorname{tr} 735$ and the $657 \Delta 5$ or $\mathrm{H} 45 \mathrm{~A}$ allele, respectively (Fig. S7, available at http://www.jem.org/cgi/content/full/ jem.20070319/DC1). Despite the persistence of a defect in Chk2 phosphorylation at low doses of IR in cells from $\mathrm{Nbs} 1^{\text {tr735/H45A }}$ and Nbs $1^{\text {tr735/65745 }}$ double-mutant mice, the cellcycle checkpoint defects, ovarian failure, and thymocyte developmental defects observed in $\mathrm{Nbs} 1^{\mathrm{H} 45 \mathrm{~A}}$ and $\mathrm{Nbs} 1^{657 \Delta 5}$ mice were completely rescued in $\mathrm{Nbs} 1^{\text {tr735/H45A }}$ and $\mathrm{Nbs} 1^{\text {tr735/657 } 5}$ mice (Fig. S7 and not depicted). Thus, expressing the tr735 mutation in the context of the $\mathrm{Nbs} 1^{657 \Delta 5}$ mutation is not fundamentally distinct from reconstitution of the Nbs1-null cells/mice.

Because conditional deletion of Nbs1 nearly abolishes ATM activity (7), there are likely to be other regions within Nbs1 or within the MRN complex that can compensate for the lack of the extreme $\mathrm{C}$ terminus. Consistent with this idea, gel filtration analysis suggests that ATM makes multiple independent direct contacts with Mre11/Rad50 and Nbs1 (6). Because the MRN complex is intact (Fig. S1), remains nuclear, and the interaction between ATM and Nbs1 is not abrogated in cells lacking the Nbs1 C terminus (Fig. 3, A and B), ATM should still be capable of binding Mre11 and Rad50 in $\mathrm{Nbs}^{\mathrm{tr} 735}$ mice. Another possibility is that mutant Nbs1 may be compensated for by the activity of other accessory proteins. For example, suppression of 53BP1 was found to decrease ATM activation in NBS but not WT cell lines (52). Consistent with this idea, recent studies by Lee et al. have demonstrated that although $\operatorname{MRN}(\Delta \mathrm{C})$ is by itself incapable of stimulating ATM kinase activity in vitro, addition of 53BP1 and Brca1 allows for efficient ATM phosphorylation of substrates (Paull, T., personal communication). Thus, one possible explanation for the observed discrepancy between our results and those based on transformed NBS cells is that these lines have acquired secondary mutations that limit the ability of adaptor proteins to affect ATM activity.

Besides functioning upstream of ATM, Nbs1 is itself a target of ATM that becomes phosphorylated at sites of DSBs (53). Surprisingly, mice expressing a nonphosphorylatable form of Nbs1 at S278 and S343 fail to demonstrate any detectable AT-like phenotype in vivo, nor do they exhibit a defect in the intra-S phase checkpoint. In contrast, NBS cell lines reconstituted with S278A and S343A failed to complement the S phase checkpoint defect (20-23). Interestingly, in NBS lymphoblastoid cells, Nbs1 ${ }^{70}$ is still phosphorylated in response to IR (54). Similarly, there is no impairment in Nbs1 phosphorylation in AT-like disorder lymphoblasts that carry a mutation in Mre11 but nevertheless express fulllength Nbs1 (54). Despite normal Nbs1 phosphorylation, both NBS and AT-like disorder cells are impaired in the induction of the $S$ phase checkpoint (54). Collectively, these results indicate that $\mathrm{Nbs} 1$ phosphorylation at S278 and S343 is neither sufficient nor necessary for inducing the $\mathrm{S}$ phase checkpoint. Although we cannot exclude that other phosphorylation sites in $\mathrm{Nbs} 1$ contribute to the intra-S phase checkpoint, we speculate that the major phenotypic overlap between AT and NBS patients is caused by a role of Nbs1 upstream rather than downstream of ATM.

Although both the $\mathrm{Nbs} 1^{\mathrm{H} 45 \mathrm{~A}}$ and the $\mathrm{Nbs} 1^{\text {tr735 }}$ mutants show a defect in Chk2 phosphorylation, only the FHA domain is required for eliciting complete DSB induced cellcycle checkpoints. In contrast, the $\mathrm{C}$ terminus is required for efficient IR-induced apoptosis. This suggests that Nbs1 may act as a molecular switch that determines alternative (cell cycle arrest vs. cell death) cellular fates in response to DSBs. This dual role may require multiple interactions between MRN and ATM and/or other mediators of the DSB response.

\section{MATERIALS AND METHODS}

Mice. Bacteria containing the BAC RPCI21-255A7 (Research Genetics) were targeted using the two-step recombination method, and mice were generated as previously described (55). The targeting was verified by sequencing of the BAC. Mice were screened as previously described (7). For crosses of $\mathrm{Nbs}^{\mathrm{tr} 735}$ mice with either $\mathrm{Nbs} 1^{\mathrm{H} 45 \mathrm{~A}}$ or $\mathrm{Nbs} 1^{657 \Delta 5}$ mice, tail screening was performed using the following primers: NBS-open reading frame (ORF; 5' -CAACATGCAAAAGAAGAGTCTC-3'), NBS-F (5'-CAACATGCATGAGAATAGTGAC-3'), and NBS-R (5'-AATCGTAATTCTACTCAGAGCTG-3'). NBS-ORF and NBS-R amplify a PCR product in $\mathrm{Nbs} 1^{\mathrm{H} 45 \mathrm{~A}}$ or $\mathrm{Nbs} 1^{657 \Delta 5}$ transgenes, whereas NBS-F and NBS-R amplify a PCR product in the $\mathrm{Nbs} 1^{\text {tr7 } 75}$ transgene.

Antibodies for Western blotting and immunofluorescence. For Western blotting, the following primary antibodies were used at the indicated dilutions: mouse anti-mouse Atm S1987p (1:500), rabbit anti-human ATM S1981p (1:400; Rockland Immunochemicals), mouse anti-human unphosphorylated ATM S1981 (1:2,500; Rockland Immunochemicals), mouse anti-ATM 5C2 (1:500; Novus), rabbit anti-Chk1 317p (1:500; Bethyl Laboratories), mouse anti-Chk2 (1:1,500; Upstate Biotechnology), mouse antitubulin (1:10,000; Sigma-Aldrich), and anti-p53 and anti-p53 S15p as previously described (5). Anti-mouse Atm 1987p monoclonal antibodies were raised by immunization with the synthetic peptide SPTFEEGSpQGTTISS (Becton Dickinson). Phosphospecific antibodies against S343-pNbs1 and S278-pNbs were a gift from E. Lee (University of Texas Health Sciences Center, San Antonio, TX). For immunofluorescence, MEFs were irradiated with a 364-nm UV laser as previously described (56), fixed with 4\% paraformaldehyde, permeabilized with $0.5 \%$ Triton X-100 for $5 \mathrm{~min}$, and stained with rabbit anti- $\boldsymbol{\gamma}-\mathrm{H} 2 \mathrm{AX}$ (1:1,000; a gift from W. Bonner, National Cancer Institute, Bethesda, MD) and mouse anti-ATM 2C1 (1:200; Santa Cruz Biotechnology, Inc.) antibodies. For foci formation, MEFs were fixed in methanol $24 \mathrm{~h}$ after IR and stained with mouse anti- $\boldsymbol{\gamma}$-H2AX (1:1,000; Upstate Biotechnology) and rabbit anti-Mre11 (raised against glutathione S-transferase [GST]-Mre11 fusion protein; Spring Valley Laboratories).

Immunoprecipitation. $30 \mathrm{~min}$ after $10 \mathrm{~Gy}$ of IR, B cells were collected, washed once in PBS, and then lysed in TNG buffer low $(50 \mathrm{mM}$ Tris- $\mathrm{HCl}$ [pH 7.5], $200 \mathrm{mM} \mathrm{NaCl}, 50 \mathrm{mM} \beta$-glyceroposphate, $0.5 \%$ Tween 20, 0.1\% NP-40) containing protease mix and PMSF. Cell lysis was done on ice for $30 \mathrm{~min}$, followed by centrifugation at $13,000 \mathrm{rpm}$ for $10 \mathrm{~min}$. Protein concentrations of the supernatant were determined by a BCA assay kit (Pierce Chemical Co.). $1 \mathrm{mg}$ of protein was precleared with protein $\mathrm{A} / \mathrm{G}$ beads (Ultralink; Pierce Chemical Co.) at $4^{\circ} \mathrm{C}$ for $1 \mathrm{~h}$ and incubated with either $3 \mu \mathrm{g} \mathrm{S1981} \mathrm{(Rockland} \mathrm{Immunochemicals)} \mathrm{or} \mathrm{Nbs1} \mathrm{(Novus)} \mathrm{antibody} \mathrm{over-}$ night at $4^{\circ} \mathrm{C}$. 20 of Ultralink protein $\mathrm{A} / \mathrm{G}$ beads were added for $1 \mathrm{~h}$ at $4^{\circ} \mathrm{C}$ to recover antibody-bound complexes. The beads were pelleted, as per the 
manufacturer's instructions, and washed twice with TNG buffer low and twice with PBS. The washed pellet was resuspended with $1 \times$ Lamelli buffer (10\% Glycerol, $3 \%$ SDS, and $0.5 \times$ Upper Tris [0.5 M Tris-HCl, $0.4 \%$ SDS] containing no dye or $\beta$-mercaptoethanol) and boiled for $10 \mathrm{~min}$ with agitation. The supernatant was recovered, and half was mixed with NuPAGE sample buffer (Invitrogen) and dithiothreitol and run on a NuPAG 4-12\% gradient gel, transferred, and blotted for ATM (5C2; Novus). The remaining fraction was run on a $6 \%$ Tris-glycine SDS gel, transferred, and blotted with anti-human Nbs1 (Novus) or anti-mouse Nbs1, as previously described (50). To determine the MRN complex assembly, immunoprecipitations were performed as described above, but protein lysis was performed in RIPA buffer using $10 \mu \mathrm{l}$ anti-Mre11 serum generated by immunizing rabbits with a GST-Mre11 fusion protein (Spring Valley Laboratories).

B cell culture, IR-induced cell-cycle checkpoints, and chromosomal stability. B cells were purified by CD43 depletion of splenocytes and cultured for $2 \mathrm{~d}$ in the presence of LPS and IL-4. For intra-S phase and G2/M checkpoints, B cells were challenged with different doses of IR and measured the thymidine uptake and mitotic index, as previously described (7). Primary MEFs were harvested $24 \mathrm{~h}$ after IR, and metaphase spreads were prepared and analyzed by DAPI staining.

Histology and apoptosis assay. Postnatal day 5 littermates were transcardially perfused with $4 \%$ paraformaldehyde in PBS $4 \mathrm{~h}$ after IR with $4 \mathrm{~Gy}$ from a cesium irradiator (at a rate of $391 \mathrm{rad} / \mathrm{min}$ ). Tissue was removed and cryoprotected in $25 \%$ PBS-buffered sucrose. $10-\mu \mathrm{m}$-thick sections were cut on a cryostat (HM500M; Microm) and used for histology and immunohistochemistry. Hematoxylin and eosin staining was performed according to standard procedures. For active caspase 3 (1:500; BD Biosciences) immunohistochemistry, sections were treated with citrate buffer for antigen retrieval after incubation with cleaved caspase 3 antibody overnight after quenching endogenous peroxidase using $0.6 \%$ hydrogen peroxide, and immunoreactivity was visualized with a substrate kit (VIP; Vector Laboratories), according to the manufacturer's direction. Sections were counterstained with $0.1 \%$ methyl green, dehydrated, and mounted in DPX (Fluka). Apoptosis was assessed by singlestranded DNA (ssDNA) immunoreactivity and TdT-mediated dUTP-biotin nick-end labeling (TUNEL). Cryosections were incubated with ssDNA antibody (1:300; IBL Co., Ltd.) overnight and visualized with indocarbocyanine (Cy3; Jackson ImmunoResearch Laboratories) mounted with Vectashield containing DAPI (Vector Laboratories). TUNEL was performed using ApopTag (Chemicon) according to the manufacturer's protocol. Images were captured with a digital camera (SPOT; Diagnostic Instruments) and processed using Photoshop CS software (Adobe). Ovaries were fixed in 10\% formalin, and paraffin sections were stained with hematoxylin and eosin.

Online supplemental material. In Fig. S1, we examined the MRN interaction in cells from WT and mutant Nbs1 mice by immunoprecipitation, and Fig. S2 shows the Mre11 and $\gamma$-H2AX foci formation in Nbs1 ${ }^{\mathrm{WT}}$, $\mathrm{Nbs} 1^{657 \Delta 5}, \mathrm{Nbs} 1^{\mathrm{H} 45 \mathrm{~A}}, \mathrm{Nbs} 1^{\mathrm{tr} 735}$, and $\mathrm{Nbs} 1^{\mathrm{S} 278 / 343 \mathrm{~A}} \mathrm{MEFs} 24 \mathrm{~h}$ after 0 or 10 Gy of IR. Fig. S3 shows chromosomal aberrations in MEFs from Nbs1 ${ }^{\mathrm{WT}}$, $\mathrm{Nbs} 1^{\mathrm{H} 45 \mathrm{~A}}, \mathrm{Nbs} 1^{657 \Delta 5}$, and $\mathrm{Nbs} 1^{\mathrm{tr} 735}$ lines before and after DNA damage induction. Fig. S4 depicts ATM substrate phosphorylation in WT and Nbs1 mutants in the presence or absence of an ATM inhibitor. Fig. S5 shows regional resistance in the cortex of the $\mathrm{Nbs} 1^{\text {tr735 }}$ mutant thymus to IR-induced apoptosis, as measured by apoptosis assays. Fig. S5 shows Western blots of p53 stabilization and phosphorylation in thymocytes from Nbs1 ${ }^{\mathrm{WT}}$, $\mathrm{Nbs} 1^{\text {tr735 }}$, and $\mathrm{Atm}^{-/-}$mice after whole-body IR and their quantitative analysis. Fig. S7 shows that the Nbs $1^{\mathrm{tr} 735}$ allele rescues cell-cycle checkpoint, oocyte, and thymocyte developmental defects but not inefficient Chk2 phosphorylation of $\mathrm{Nbs} 1^{657 \Delta 5}$ mice. Online supplemental material is available at http://www.jem.org/cgi/content/full/jem.20070319/DC1.

Thanks to Eva Lee for providing antibodies; David Winkler, Hua-Tang Chen, Steve Jay, and Nada Radoja for technical assistance; and Tanya Paull for sharing unpublished results.
This work was supported by the Intramural Research Program of the National Institutes of Health, the National Cancer Institute, the Center for Cancer Research, the National Institute of Aging, and a grant from the A-T Children's Project.

The authors have no conflicting financial interests.

\section{Submitted: 12 February 2007}

Accepted: 13 April 2007

\section{REFERENCES}

1. Uziel, T., Y. Lerenthal, L. Moyal, Y. Andegeko, L. Mittelman, and Y. Shiloh. 2003. Requirement of the MRN complex for ATM activation by DNA damage. EMBO J. 22:5612-5621.

2. Horejsi, Z., J. Falck, C.J. Bakkenist, M.B. Kastan, J. Lukas, and J. Bartek. 2004. Distinct functional domains of Nbs1 modulate the timing and magnitude of ATM activation after low doses of ionizing radiation. Oncogene. 23:3122-3127.

3. Cerosaletti, K., and P. Concannon. 2004. Independent roles for nibrin and Mre11-Rad50 in the activation and function of Atm. J. Biol. Chem. 279:38813-38819.

4. Carson, C.T., R.A. Schwartz, T.H. Stracker, C.E. Lilley, D.V. Lee, and M.D. Weitzman. 2003. The Mre11 complex is required for ATM activation and the G2/M checkpoint. EMBO J. 22:6610-6620.

5. Costanzo, V., T. Paull, M. Gottesman, and J. Gautier. 2004. Mre11 assembles linear DNA fragments into DNA damage signaling complexes. PLoS Biol. 2:E110.

6. Lee, J.H., and T.T. Paull. 2004. Direct activation of the ATM protein kinase by the Mre11/Rad50/Nbs1 complex. Science. 304:93-96.

7. Difilippantonio, S., A. Celeste, O. Fernandez-Capetillo, H.T. Chen, B Reina San Martin, F. Van Laethem, Y.P. Yang, G.V. Petukhova, M. Eckhaus, L. Feigenbaum, et al. 2005. Role of Nbs1 in the activation of the Atm kinase revealed in humanized mouse models. Nat. Cell Biol. 7:675-685.

8. D'Amours, D., and S.P. Jackson. 2002. The Mre11 complex: at the crossroads of DNA repair and checkpoint signalling. Nat. Rev. Mol. Cell Biol. 3:317-327.

9. Stracker, T.H., J.W. Theunissen, M. Morales, and J.H. Petrini. 2004. The Mre11 complex and the metabolism of chromosome breaks: the importance of communicating and holding things together. DNA Repair (Amst.). 3:845-854.

10. Xiao, Y., and D.T. Weaver. 1997. Conditional gene targeted deletion by Cre recombinase demonstrates the requirement for the double-strand break repair Mre11 protein in murine embryonic stem cells. Nucleic Acids Res. 25:2985-2991.

11. Luo, G., M.S. Yao, C.F. Bender, M. Mills, A.R. Bladl, A. Bradley, and J.H. Petrini. 1999. Disruption of mRad50 causes embryonic stem cell lethality, abnormal embryonic development, and sensitivity to ionizing radiation. Proc. Natl. Acad. Sci. USA. 96:7376-7381.

12. Zhu, J., S. Petersen, L. Tessarollo, and A. Nussenzweig. 2001. Targeted disruption of the Nijmegen breakage syndrome gene NBS1 leads to early embryonic lethality in mice. Curr. Biol. 11:105-109.

13. Yamaguchi-Iwai, Y., E. Sonoda, M.S. Sasaki, C. Morrison, T. Haraguchi, Y. Hiraoka, Y.M. Yamashita, T. Yagi, M. Takata, C. Price, et al. 1999. Mre11 is essential for the maintenance of chromosomal DNA in vertebrate cells. EMBO J. 18:6619-6629.

14. Reina-San-Martin, B., M.C. Nussenzweig, A. Nussenzweig, and S. Difilippantonio. 2005. Genomic instability, endoreduplication, and diminished Ig class-switch recombination in B cells lacking Nbs1. Proc. Natl. Acad. Sci. USA. 102:1590-1595.

15. Yang, Y.G., A. Saidi, P.O. Frappart, W. Min, C. Barrucand, V. DumonJones, J. Michelon, Z. Herceg, and Z.Q. Wang. 2006. Conditional deletion of Nbs1 in murine cells reveals its role in branching repair pathways of DNA double-strand breaks. EMBO J. 25:5527-5538.

16. Buscemi, G., C. Savio, L. Zannini, F. Micciche, D. Masnada, M. Nakanishi, H. Tauchi, K. Komatsu, S. Mizutani, K. Khanna, et al. 2001 Chk2 activation dependence on Nbs1 after DNA damage. Mol. Cell. Biol. 21:5214-5222.

17. Demuth, I., P.O. Frappart, G. Hildebrand, A. Melchers, S. Lobitz, L. Stockl, R. Varon, Z. Herceg, K. Sperling, Z.Q. Wang, and M. Digweed. 2004. An inducible null mutant murine model of Nijmegen 
breakage syndrome proves the essential function of NBS1 in chromosomal stability and cell viability. Hum. Mol. Genet. 13:2385-2397.

18. Kang, J., R.T. Bronson, and Y. Xu. 2002. Targeted disruption of NBS1 reveals its roles in mouse development and DNA repair. EMBO J. 21:1447-1455.

19. Kang, J., D. Ferguson, H. Song, C. Bassing, M. Eckersdorff, F.W. Alt, and Y. Xu. 2005. Functional interaction of H2AX, NBS1, and p53 in ATM-dependent DNA damage responses and tumor suppression. Mol. Cell. Biol. 25:661-670.

20. Gatei, M., D. Young, K.M. Cerosaletti, A. Desai-Mehta, K. Spring, S. Kozlov, M.F. Lavin, R.A. Gatti, P. Concannon, and K. Khanna. 2000. ATM-dependent phosphorylation of nibrin in response to radiation exposure. Nat. Genet. 25:115-119.

21. Lim, D.S., S.T. Kim, B. Xu, R.S. Maser, J. Lin, J.H. Petrini, and M.B. Kastan. 2000. ATM phosphorylates p95/nbs1 in an S-phase checkpoint pathway. Nature. 404:613-617.

22. Wu, X., V. Ranganathan, D.S. Weisman, W.F. Heine, D.N. Ciccone, T.B. O’Neill, K.E. Crick, K.A. Pierce, W.S. Lane, G. Rathbun, et al. 2000. ATM phosphorylation of Nijmegen breakage syndrome protein is required in a DNA damage response. Nature. 405:477-482.

23. Zhao, S., Y.C. Weng, S.S. Yuan, Y.T. Lin, H.C. Hsu, S.C. Lin, E. Gerbino, M.H. Song, M.Z. Zdzienicka, R.A. Gatti, et al. 2000 Functional link between ataxia-telangiectasia and Nijmegen breakage syndrome gene products. Nature. 405:473-477.

24. Lukas, C., F. Melander, M. Stucki, J. Falck, S. Bekker-Jensen, M. Goldberg, Y. Lerenthal, S.P. Jackson, J. Bartek, and J. Lukas. 2004. Mdc1 couples DNA double-strand break recognition by Nbs1 with its H2AX-dependent chromatin retention. EMBO J. 23:2674-2683.

25. Falck, J., J. Coates, and S.P. Jackson. 2005. Conserved modes of recruitment of ATM, ATR and DNA-PKcs to sites of DNA damage. Nature. 434:605-611.

26. Cerosaletti, K., J. Wright, and P. Concannon. 2006. Active role for nibrin in the kinetics of atm activation. Mol. Cell. Biol. 26:1691-1699.

27. Bakkenist, C.J., and M.B. Kastan. 2003. DNA damage activates ATM through intermolecular autophosphorylation and dimer dissociation. Nature. 421:499-506.

28. Pellegrini, M., A. Celeste, S. Difilippantonio, R. Guo, W. Wang, L. Feigenbaum, and A. Nussenzweig. 2006. Autophosphorylation at serine 1987 is dispensable for murine Atm activation in vivo. Nature. 443:222-225.

29. Lee, J.H., and T.T. Paull. 2005. ATM activation by DNA double-strand breaks through the Mre11-Rad50-Nbs1 complex. Science. 308:551-554.

30. Fernandez-Capetillo, O., A. Celeste, and A. Nussenzweig. 2003. Focusing on foci: $\mathrm{H} 2 \mathrm{AX}$ and the recruitment of DNA-damage response factors. Cell Cycle. 2:426-427.

31. Fernandez-Capetillo, O., H.T. Chen, A. Celeste, I. Ward, P.J. Romanienko, J.C. Morales, K. Naka, Z. Xia, R.D. Camerini-Otero, N. Motoyama, et al. 2002. DNA damage-induced G2-M checkpoint activation by histone H2AX and 53BP1. Nat. Cell Biol. 4:993-997.

32. Xu, Y., and D. Baltimore. 1996. Dual roles of ATM in the cellular response to radiation and in cell growth control. Genes Dev. 10:2401-2410.

33. Herzog, K.H., M.J. Chong, M. Kapsetaki,J.I. Morgan, and P.J. McKinnon. 1998. Requirement for Atm in ionizing radiation-induced cell death in the developing central nervous system. Science. 280:1089-1091.

34. Carney, J.P., R.S. Maser, H. Olivares, E.M. Davis, M. Le Beau, J.R. Yates III, L. Hays, W.F. Morgan, and J.H. Petrini. 1998. The hMre11/ hRad50 protein complex and Nijmegen breakage syndrome: linkage of double-strand break repair to the cellular DNA damage response. Cell. 93:477-486.

35. Stewart, G.S., R.S. Maser, T. Stankovic, D.A. Bressan, M.I. Kaplan, N.G. Jaspers, A. Raams, P.J. Byrd, J.H. Petrini, and A.M. Taylor. 1999. The DNA double-strand break repair gene hMRE11 is mutated in individuals with an ataxia-telangiectasia-like disorder. Cell. 99:577-587.

36. Zhao, S., W. Renthal, and E.Y. Lee. 2002. Functional analysis of FHA and BRCT domains of NBS1 in chromatin association and DNA damage responses. Nucleic Acids Res. 30:4815-4822.

37. Cerosaletti, K.M., and P. Concannon. 2003. Nibrin forkhead-associated domain and breast cancer $\mathrm{C}$-terminal domain are both required for nuclear focus formation and phosphorylation. J. Biol. Chem. 278: 21944-21951.

38. Kobayashi, J., H. Tauchi, S. Sakamoto, A. Nakamura, K. Morishima, S. Matsuura, T. Kobayashi, K. Tamai, K. Tanimoto, and K. Komatsu. 2002. NBS1 localizes to gamma-H2AX foci through interaction with the FHA/BRCT domain. Curr. Biol. 12:1846-1851.

39. Stucki, M., and S.P. Jackson. 2006. gammaH2AX and MDC1: anchoring the DNA-damage-response machinery to broken chromosomes. DNA Repair (Amst.). 5:534-543.

40. Lee, J.H., B. Xu, C.H. Lee, J.Y. Ahn, M.S. Song, H. Lee, C.E. Canman, J.S. Lee, M.B. Kastan, and D.S. Lim. 2003. Distinct functions of Nijmegen breakage syndrome in ataxia telangiectasia mutateddependent responses to DNA damage. Mol. Cancer Res. 1:674-681.

41. Tauchi, H., J. Kobayashi, K. Morishima, S. Matsuura, A. Nakamura, T. Shiraishi, E. Ito, D. Masnada, D. Delia, and K. Komatsu. 2001. The forkhead-associated domain of NBS1 is essential for nuclear foci formation after irradiation but not essential for hRAD50[middle dot]hMRE11[middle dot]NBS1 complex DNA repair activity. J. Biol. Chem. 276:12-15.

42. Kim, S.T., B. Xu, and M.B. Kastan. 2002. Involvement of the cohesin protein, Smc1, in Atm-dependent and independent responses to DNA damage. Genes Dev. 16:560-570.

43. Kitagawa, R., C.J. Bakkenist, P.J. McKinnon, and M.B. Kastan. 2004. Phosphorylation of SMC1 is a critical downstream event in the ATMNBS1-BRCA1 pathway. Genes Dev. 18:1423-1438.

44. Durocher, D., and S.P. Jackson. 2002. The FHA domain. FEBS Lett. 513:58-66

45. Yazdi, P.T., Y. Wang, S. Zhao, N. Patel, E.Y. Lee, and J. Qin. 2002. SMC1 is a downstream effector in the ATM/NBS1 branch of the human S-phase checkpoint. Genes Dev. 16:571-582.

46. You, Z., C. Chahwan, J. Bailis, T. Hunter, and P. Russell. 2005. ATM activation and its recruitment to damaged DNA require binding to the C terminus of Nbs1. Mol. Cell. Biol. 25:5363-5379.

47. Nakada, D., K. Matsumoto, and K. Sugimoto. 2003. ATM-related Tel1 associates with double-strand breaks through an Xrs2-dependent mechanism. Genes Dev. 17:1957-1962.

48. Dupre, A., L. Boyer-Chatenet, and J. Gautier. 2006. Two-step activation of ATM by DNA and the Mre11-Rad50-Nbs1 complex. Nat. Struct. Mol. Biol. 13:451-457.

49. Maser, R.S., R. Zinkel, and J.H. Petrini. 2001. An alternative mode of translation permits production of a variant NBS1 protein from the common Nijmegen breakage syndrome allele. Nat. Genet. 27:417-421.

50. Chen, H.T., A. Bhandoola, M.J. Difilippantonio, J. Zhu, M.J. Brown, X. Tai, E.P. Rogakou, T.M. Brotz, W.M. Bonner, T. Ried, and A. Nussenzweig. 2000. Response to RAG-mediated VDJ cleavage by NBS1 and gamma-H2AX. Science. 290:1962-1965.

51. Hickson, I., Y. Zhao, C.J. Richardson, S.J. Green, N.M. Martin, A.I. Orr, P.M. Reaper, S.P. Jackson, N.J. Curtin, and G.C. Smith. 2004. Identification and characterization of a novel and specific inhibitor of the ataxia-telangiectasia mutated kinase ATM. Cancer Res. 64: 9152-9159

52. Mochan, T.A., M. Venere, R.A. DiTullio Jr., and T.D. Halazonetis. 2003. 53BP1 and NFBD1/MDC1-Nbs1 function in parallel interacting pathways activating ataxia-telangiectasia mutated (ATM) in response to DNA damage. Cancer Res. 63:8586-8591.

53. Lukas, C., J. Falck, J. Bartkova, J. Bartek, and J. Lukas. 2003. Distinct spatiotemporal dynamics of mammalian checkpoint regulators induced by DNA damage. Nat. Cell Biol. 5:255-260.

54. Maser, R.S., O.K. Mirzoeva, J. Wells, H. Olivares, B.R. Williams, R.A. Zinkel, P.J. Farnham, and J.H. Petrini. 2001. Mre11 complex and DNA replication: linkage to E2F and sites of DNA synthesis. Mol. Cell. Biol. 21:6006-6016.

55. Yang, Y., and S.K. Sharan. 2003. A simple two-step, 'hit and fix' method to generate subtle mutations in BACs using short denatured PCR fragments. Nucleic Acids Res. 31:e80.

56. Kruhlak, M.J., A. Celeste, G. Dellaire, O. Fernandez-Capetillo, W.G. Muller, J.G. McNally, D.P. Bazett-Jones, and A. Nussenzweig. 2006. Changes in chromatin structure and mobility in living cells at sites of DNA double-strand breaks. J. Cell Biol. 172:823-834. 